\title{
Evaluation of ground-level and space-borne sensor as tools in monitoring nitrogen nutrition status in immature and mature oil palm
}

\begin{abstract}
Monitoring nitrogen $(\mathrm{N})$ in oil palm is crucial for the production sustainability. The objective of this study is to examine the capability of visible (Vis), near infrared (NIR) and a combination of Vis and NIR (Vis + NIR) spectral indices acquired from different sensors for predicting foliar $\mathrm{N}$ content of different palm age groups. The $\mathrm{N}$ treatments varied from 0 to 2 $\mathrm{kg}$ per palm, subjected according to immature, young mature and prime mature classes. The Vis + NIR indices from the ground level-sensor that is green + red + NIR (G + R + NIR) was the best index for predicting $\mathrm{N}$ for immature palms $(\mathrm{R} 2=0.91)$, while Vis indices blue + red $(\mathrm{B}+\mathrm{R})$ and Green Red Index from the space-borne sensor were significantly useful for $\mathrm{N}$ assessment of young and prime mature palms $(\mathrm{R} 2=0.70$ and 0.50$)$, respectively. The application of vegetation indices for monitoring $\mathrm{N}$ status of oil palm is beneficial to examine extensive plantation areas.
\end{abstract}

Keyword: Ground-level; Nitrogen; Oil palm; Space-borne 